\title{
Beyond the bench: A conversation with Konstantinos Zarbalis
}

\author{
BY DELIA O'HARA
}

10 FEBRUARY 2022

Neuroscientist Konstantinos Zarbalis had a "mostly Greek upbringing" while growing up in Germany, he says. His father, who was born in Greece, was a cantor in a Greek Orthodox church in Munich, Germany, and Kostas, as he is known, attended a Greek school until university, completing a Ph.D. in molecular biology and genetics at the Technical University of Munich.

"My sizeable extended family and all my school friends were Greek," he says. German was his second language and English his third.

Zarbalis is now associate professor of pathology and laboratory medicine at the University of California, Davis (UC Davis) and associate investigator at the Shriners Hospital for Children in Sacramento - roles in which he uses mouse models to explore what happens before birth in the developing brain.

On weekends, Zarbalis travels from Sacramento to the San Francisco Bay Area to connect with his family and "do the typical family stuff," he says. And with more pandemic-enforced leisure time over the past two years, he has picked up an old hobby - playing classical guitar, which he learned at the age of 20. Coming back to the guitar after a decade of not playing hasn't been easy, he says, but it has been rewarding.

Zarbalis talked to Spectrum about how satisfying it can also be to have an experiment produce unexpected results and why he ordinarily eats only one meal a day.

\section{Spectrum: What big question drives your research?}

Konstantinos Zarbalis: What is of greatest interest to me are the molecular and cellular processes that, during prenatal development, guide the formation of the brain and its individual structures. And, of course, I'm also interested in how these processes may be dysregulated in 


\section{Spectrum | Autism Research News}

https://staging.spectrumnews.org

autism.

\section{S: Whose work do you admire?}

KB: John Rubenstein, who is at the University of California, San Francisco, has made great contributions to our understanding of the prenatal developmental processes that guide the formation of the brain, and how disease states influence changes in prenatal development. I've had the pleasure of collaborating a little bit with him. And Nenad Sestan at Yale University; I find his comparative and longitudinal transcriptional brain analysis particularly interesting — how it sheds light on the specifics of human brain evolution and function. I also really admire some of the people who are working in the cerebral and cortical organoid field, like Sergiu Pasca at Stanford University.

One of the reasons why I wanted to come to the United States to work was because the field of developmental neuroscience was so strongly represented here. It was the work of American researchers I followed early on that motivated me to pursue my own research career in this area.

\section{S: What is the most rewarding part of your job?}

KZ: Interacting with really smart and capable people and exchanging ideas, contemplating problems, trying to find solutions together. I'm including the people in my own lab, but also the community at UC Davis and even beyond. One thing that's even a little more personal is just the satisfaction to see an experiment succeed, to see that an idea, put to the test, can actually produce the outcome that was anticipated - or maybe, surprisingly, produce a different outcome that is just as exciting and interesting.

\section{S: What does your typical day look like?}

KZ: I get up at 6 a.m., maybe do a brief workout. Then I have breakfast, and it's usually a generous breakfast, all the major food groups, because that will typically be my only meal during the day. Then I go to the lab and spend, I would say, 10 hours there on average. Midday or in the evening, I hit the gym. The pandemic has done a major disservice to my workout routine, but thankfully, the gym is open right now. In summer, in addition, I take an evening swim.

\section{S: Why do you eat only one meal a day?}

KZ: Intermittent fasting helps me maintain a healthy lifestyle - which appears to be well supported by research - and I think I feel better doing it. The other reason is, this way food is never on the agenda while I'm at work, so I can fully concentrate on the tasks at hand. I'm a big tea drinker, though. I have black tea in the morning and green tea throughout the day. 


\section{S: When and where are you most productive?}

KZ: In my office. It's quiet and has the best setup for me for work, with my computer and my fast network and all that.

\section{S: Do you listen to music or podcasts while you work?}

KZ: Not when l'm working intensely. I'm too distractable. I try to keep it as quiet as possible when I'm writing or reading. But when I'm doing tasks that are not as demanding, like putting figures together or sorting papers, things like that, then sometimes I listen to some music, rock music, Maserati, Majeure or Zombi, soundtracks — something without vocals.

\section{S: What conferences do you like?}

KZ: The Society for Neuroscience conference gives me the opportunity to look at a wide variety of research and meet a lot of people, some of whom are not from my field but maybe have good ideas that can help me advance my own research, or some interesting insights. The other conference I like is the Cortical Development Conference that, until recently, happened every three years in Greece.

\section{S: What do you read for pleasure?}

KZ: I mostly read nonfiction books. Currently, that's "Lifespan: Why We Age - and Why We Don't Have To," by David Sinclair, and "Loot: The Battle Over the Stolen Treasures of the Ancient World," by Sharon Waxman, which touches on my other big area of intellectual interest: ancient history and archaeology.

\section{S: Does your lab have any traditions?}

KZ: This is a violation of my typical rule of intermittent fasting, but sometimes we go for dinner as a lab, hitting some of the nice restaurants in Sacramento for all kinds of occasions, but particularly when people are coming in or departing.

\section{S: Are you active on social media?}

KZ: I'm not, unless you count Linkedln. I wouldn't know where to find the time to be engaged with social media.

\section{S: How many unread emails are in your inbox right now?}

KZ: Zero. Always zero. I'm too obsessive-compulsive to see this red circle with a number in it flashing up on my screen. 


\section{Spectrum | Autism Research News}

https://staging.spectrumnews.org

Cite this article: https://doi.org/10.53053/XFCF7257 